\title{
E-MRS Issues Call for Papers for 20th Anniversary Meeting
}

Celebrating its 20th anniversary, the European Materials Research Society will hold its 2003 Spring Meeting in Strasbourg, France, from June 10-13. Chaired by P. Glasow (Erlangen, Germany), F. Priolo (Università di Catania, Italy), M. Stuke (Max-Planck-Institut, Germany), and G. Crean (University College, Ireland), the meeting will cover progress in the field of advanced materials. The objectives of the meeting are to promote and enhance the efficiency of research in European countries and to provide information on the development of science and technology worldwide through E-MRS's connections with other member societies within the International Union of Materials Research Societies (IUMRS).

The E-MRS 2003 Spring Meeting will include a plenary session, a graduate student award ceremony, a conference reception, an industrial exhibit, and 16 symposia running in parallel:

- Symposium A: Current Trends in Nanoscience-From Materials to Application
- Symposium B: Advanced Multifunctional Nanocarbon Materials and Nanosystems

- Symposium C: Nanoscale Materials for Energy Storage

- Symposium D: Thin-Film and Nanostructured Materials for Photovoltaics

- Symposium E: Ion Beams for Nanoscale Surface Modifications

- Symposium F: Nanostructures from Clusters

- Symposium G: Protective Coatings and Thin Films-03

- Symposium H: Photonic Processing of Surfaces, Thin Films, and Devices

- Symposium I: Functional Metal OxidesSemiconductor Structures

- Symposium J: Rare-Earth-Doped

Materials for Photonics

- Symposium K: Design, Characterization, and Modeling of Molecule-Based Magnetic Materials

- Symposium L: Carbon Materials for Active Electronics

- Symposium M: Optical and X-Ray
Metrology for Advanced Device Materials Characterization

- Symposium N: New Materials and Technologies in Sensor Applications

- Symposium O: Materials Aspects of Art Characterization Conservation and Restoration

- Symposium P: Current Trends in Crystalline Organic Semiconductors: Growth, Growth Modeling, and Fundamental Properties.

The abstract deadline is January 14, 2003. Proceedings will be published by Elsevier/North Holland.

For more information, visit the E-MRS Web site at http://www-emrs.c-strasbourg. fr or contact the E-MRS General Secretary, Paul Siffert, at E-MRS Headquarters, BP 20, 67037, Strasbourg Cedex 2, France; tel. 33-3-88-10-63-72, fax 3-88-10-63-43, or e-mail emrs@phase.c-strasbourg.fr.

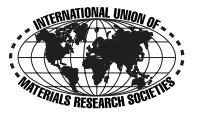

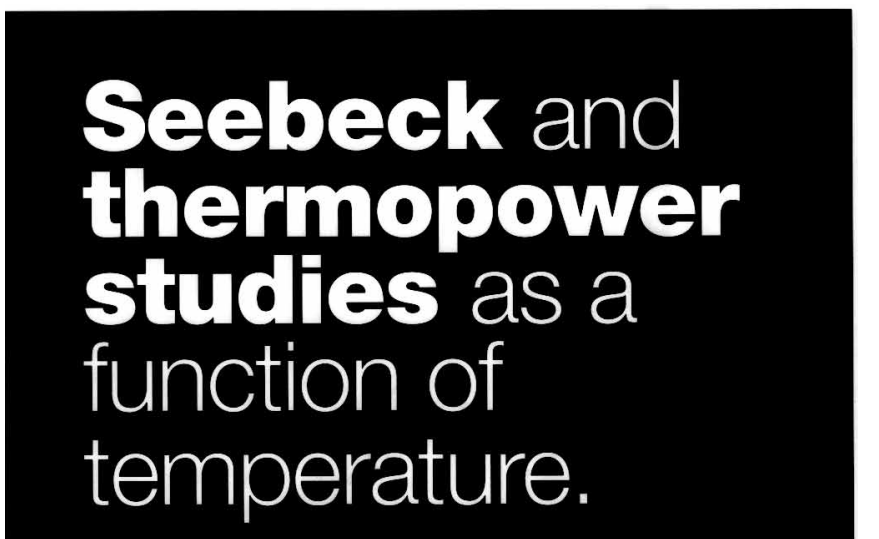

MMR Technologies has developed an

instrument, never before commercially available.

which facilitates convenient and straight-forward

measurement of the Seebeck Effect (thermopower

coefficient) of semiconductors, conductive

ceramics, conductive organics and

polymers, and conventional metals

over a wide temperature range, $\mathbf{8 0 K - 7 3 0 k}$

$(-190 \mathrm{C}$ to $+450 \mathrm{C})$

MMR MMR Technologies, Inc.

For information call 650 / 962-9620 or visit our website at http://www. mm m.com

Circle No. 15 on Inside Back Cover

\section{MRS BULLETIN SEEKS IUMRS NEWS ON}

- Upcoming Meetings

- Conference Reports

- Important Technical Developments

- Research News

- Policy Issues

- Educational Initiatives

MRS Bulletin, Materials Research Society

506 Keystone Drive, Warrendale, PA 15086-7573 USA

E-mail: bulletin@mrs.org

Fax: 724-779-8313

\section{Advertisers in This Issue}

Page No.

Chemat Technology, Inc.

943

High Voltage Engineering

Inside front cover

Huntington Mechanical

Laboratories, Inc.

Outside back cover

MMR Technologies, Inc.

945,988

MTS Systems Corp.

950

For free information about the products and services offered in this issue, check www.mrs.org/publications/bulletin/advertisers or fax the inside back cover to 724-779-4397. 